\title{
Predation rates of Indo-Pacific lionfish on Bahamian coral reefs
}

\author{
Isabelle M. Côté*, Aleksandra Maljković \\ Department of Biological Sciences, Simon Fraser University, Burnaby, British Columbia V5A 1S6, Canada
}

\begin{abstract}
Indo-Pacific lionfish, mainly Pterois volitans, are currently invading coral reefs throughout the Caribbean region, where they have the potential to outcompete and prey upon a wide range of native reef animals. Here, we derive the first estimates of rates of predation by lionfish from field observations on natural reefs around New Providence, Bahamas. Although lionfish are reported to be crepuscular in their native range, they were very active during daylight hours. Lionfish were observed hunting at least 19 reef fish species, in at least 9 families. They hunted significantly more on overcast days and at greater depths, and frequently hunted near aggregations of fish at cleaning stations. Lionfish consumed native fish at an average rate of $1.44 \mathrm{kills} \mathrm{h}^{-1}\left(0.29 \mathrm{kills} \mathrm{h}^{-1}\right.$ on clear days and 2.29 kills $\mathrm{h}^{-1}$ on overcast days). This estimate may be conservative if lionfish hunt also between dusk and dawn. This rate is considerably higher than the only known prey consumption rate for $P$. volitans, which is extrapolated from ad libitum feeding of fish from the native range. Our results imply that using published predation rates from the native range to predict the impacts of lionfish on native Caribbean fish could lead to severe underestimation of these impacts.
\end{abstract}

KEY WORDS: Behavioural observations - Biological invasions - Foraging strategies - Marine introductions $\cdot$ Predator-prey interactions $\cdot$ Turkeyfish

\section{INTRODUCTION}

Biological invasions are a major agent of global change (Vitousek et al. 1997, Ruiz et al. 1999, 2000). In the marine environment, non-indigenous species have been reported in most regions of the world and their introductions are almost invariably human-mediated (Carlton 1989, Ruiz et al. 1997, 2000). The extent and cumulative impact of these invasions are often poorly understood but many have the potential to have extreme ecological and economic consequences.

One recent introduction that is attracting attention and generating concern is that of Indo-Pacific lionfish in the Western Atlantic. Small numbers of 2 closely related species of predatory lionfish (Pterois volitans and $P$. miles) were first recorded in eastern US coastal waters in 1992 (Courtenay 1995). The sources of introduction are likely to be accidental releases from aquaria (Semmens et al. 2004), probably in Florida, which is the location of the first records in US waters
(Whitfield et al. 2002, Ruiz-Carus et al. 2006). This invasion route is probable given that lionfish are popular in the aquarium trade (Wabnitz et al. 2003). Moreover, an accidental release from an aquarium in Biscayne Bay, Florida, occurred during Hurricane Andrew in 1992 (Courtenay 1995). Genetic evidence suggests either a single introduction of a small founding population or multiple introductions of individuals with the same haplotype (Hamner et al. 2007).

Since 2000, lionfish (mostly Pterois volitans; Hamner et al. 2007, Freshwater et al. 2009) have spread rapidly, first northward along the southeast coast of the USA and then eastward and southward into the Caribbean. They have now been sighted as far as Bermuda to the northeast, Massachussetts, USA, to the northwest, Barbados to the southeast and Belize to the southwest (reviewed by Morris et al. 2009). The genetic similarity between lionfish from the eastern US coast and the Bahamas suggests that the sources of Bahamian lionfish are eggs and larvae dispersing from the USA 
(Freshwater et al. 2009). In some areas, e.g. North Carolina, lionfish have become more abundant than native groupers, which are functionally equivalent (Whitfield et al. 2007), and the maximum densities recently reported on Bahamian reefs (>390 fish ha ${ }^{-1}$; Green \& Côté 2009) appear to exceed the few existing estimates reported from their native range (Fishelson 1997) and other parts of their introduced range (i.e. southeastern US coast; Whitfield et al. 2007).

Lionfish pose a major threat to coral reef ecosystems in the Caribbean region. They have the potential to outcompete and prey upon a wide range of native reef animals. On small experimental reefs in the Bahamas, young lionfish reduced recruitment of native reef fish by nearly $80 \%$ (Albins \& Hixon 2008). The impacts of lionfish on natural reefs, where lionfish densities are higher (Green \& Côté 2009) and large adult lionfish are abundant (authors' pers. obs.), have not yet been evaluated, but these could be even more profound if predation rates are high and the targets include reproductively valuable adult prey.

In this paper, we present the first estimates of predation rates by Indo-Pacific lionfish from natural reefs in their introduced range. We documented the behavioural strategies and prey of lionfish, and examined environmental correlates of 4 aspects of lionfish activity level and predation behaviour, namely time spent active, time spent hunting, distance moved and the rate of predation attempts.

\section{MATERIALS AND METHODS}

Study site. The study was carried out in January 2009 along a continuous coral reef wall off the southwest coast of New Providence Island, Bahamas. The 5 study sites (Runway, DC3 Wall, Willaurie, Bond Wrecks and Pumpkin Patch) were separated by at least $450 \mathrm{~m}$. Observations of lionfish were made across the reef flat, and along the top of the wall at each site (depth range: 9 to $33.5 \mathrm{~m}$ ). Lionfish were abundant at all sites.

Field observations. We carried out one 10 min observation on each of 96 lionfish located during random SCUBA-diving swims. We noted the start time of each search. To prevent potential bias associated with the heightened conspicuousness of active lionfish, the random swims were carried out close $(<1 \mathrm{~m})$ to the substratum and included thorough searches of caves, large crevices and coral overhangs that could provide shelter to inactive lionfish settled on the substratum. This method appeared to control bias effectively, since the time to detection of the first lionfish on each dive did not vary with lionfish activity (mean $\pm \mathrm{SE}$, first lionfish active: $13.7 \pm 3.2 \mathrm{~min}, \mathrm{n}=16$; first lionfish inactive:
$11.6 \pm 1.2 \min , \mathrm{n}=16$; $t$-test for unequal variances, $t=$ $0.96, \mathrm{df}=21.15, \mathrm{p}=0.35$ ), nor did the time to locate the second of 2 consecutive lionfish (next lionfish active: $4.2 \pm 0.6 \mathrm{~min}$, next lionfish inactive: $3.5 \pm 0.7 \mathrm{~min} ; t$-test for equal variances, $t=0.65, \mathrm{df}=38, \mathrm{p}=0.52$ ). After the first sighting and observation, lionfish were then selected on a next-to-encounter basis.

At the onset of each observation, we noted the time, depth (to nearest $0.1 \mathrm{~m}$, with a dive computer), cloud cover (as clear or overcast, i.e. $>70 \%$ cloud cover), lionfish total length (TL) (to the nearest $2 \mathrm{~cm}$ by visual assessment) and whether the lionfish was active (i.e. swimming or hovering in the water column, or moving along the substratum) or inactive (i.e. resting motionless on the substratum). We recorded the time spent active and inactive, and the length of each hunting bout (i.e. a period of continuous hunting activity), from which we calculated the total time spent hunting in each 10 min period. Hunting was recorded when lionfish adopted a specific posture, with pectoral rays spread out and fins externally rotated, parallel to the transverse plane of the body. This posture was usually accompanied by a head-down position. The finspreading associated with hunting is also shown by lionfish in response to close encounters with divers (authors' pers. obs.). However, lionfish in defensive posture usually hold a horizontal stance and slowly swim away from the perceived threat. The good visibility $(\geq 20 \mathrm{~m})$ made it easy to determine whether lionfish were already in hunting posture before we reached our target observation distance (approx. 2 to $3 \mathrm{~m}$ from focal fish). Moreover, in our experience, divers at or beyond this distance do not elicit notable changes in lionfish behaviour. We recorded the apparent target(s) of each hunting bout, any predation attempt and the outcome of such events (i.e. successful or unsuccessful). Unsuccessful events included all truly unsuccessful attempts (i.e. the prey escaped) as well as those where the outcome was ambiguous (e.g. no prey was seen swimming away but the lionfish immediately resumed the hunting posture after lunging; $\mathrm{n}=2$ occasions). At the end of each observation, we noted the approximate distance (in $\mathrm{m}$ ) moved by the lionfish.

Between 16 and 22 lionfish were observed over 3 to 6 dives at each of the 5 study sites. To minimise the chance of observing the same individual twice, observations were carried out at different locations of each study site on each dive. Given the high abundance of lionfish at all study sites, the likelihood of repeat observations was low.

Analysis. We first calculated rates of attempted and successful predation by tallying all such events across all fish observed and dividing by total observation time. Note that because unsuccessful predation attempts include attempts with ambiguous outcomes, 
our measures of successful predation are conservative. Lionfish that spent their entire observation period on the substratum were categorised as inactive, and the predation rates of active or inactive lionfish were compared.

There were no consistent, statistically significant differences among sites in lionfish foraging (i.e. rate of predation attempts, rate of prey captured, predation success by lionfish) (Kruskal-Wallis tests, $\chi^{2}<9.25$, df $=$ $4, \mathrm{p}>0.06$ in all cases). All sites were therefore combined in subsequent analyses. We examined the effects of time of day ( 2 categories: morning vs. afternoon), cloud cover (2 categories: clear vs. overcast), depth (continuous covariate) and fish TL (continuous covariate) on 4 aspects of lionfish activity level and predation behaviour, namely (1) time spent active, (2) time spent hunting, (3) distance moved and (4) the number of predation attempts per $10 \mathrm{~min}$. Because the assumptions of parametric testing could not be met, we examined each correlate separately, and altered the significance threshold by applying the false discovery rate (FDR) correction (Benjamini \& Hochberg 1995) across the set of 16 tests. The corrected significance threshold, $\alpha_{\text {FDR }}$, is given for each significant test.

Because of the influence of cloud cover on lionfish activity levels (see 'Results'), atypical cloud cover during the study could bias estimated predation rates. To examine whether the cloudiness during the study period was typical at our study location and to corroborate our field measurements of cloud cover, we obtained information on cloud cover from an online meteorological information archive (www. wunderground.com, accessed 30 April 2009). Weather was reported hourly from the Nassau International Airport, and cloud cover recorded as clear, few $(1 / 8$ to $2 / 8$ cloud cover), scattered $(3 / 8$ to $4 / 8)$, broken $(5 / 8$ to $6 / 8)$ or overcast $(8 / 8)$. 'Few' and 'scattered' were also sometimes reported as 'partly' cloudy, and 'broken' and 'overcast' as 'mostly' cloudy. We noted the most frequent hourly descriptor of cloudiness between 10:00 and 15:00 $\mathrm{h}$ on each of 6 days per month (the 5th, 10th, 15th, 20th, 25th, and last day) from 1 May 2008 to 30 April 2009. 'Broken', 'overcast' and 'mostly' were deemed to be equivalent to our 'overcast' category. We then compared with a $\chi^{2}$ test the numbers of clear and overcast observation periods during our study to an expectation derived from the archive data.

\section{RESULTS}

\section{Predations rates and targets}

In $16 \mathrm{~h}$ of observation, we witnessed 233 hunting bouts $\left(\right.$ mean \pm SE: $2.43 \pm 0.30$ bouts lionfish ${ }^{-1} 10 \mathrm{~min}^{-1}$ ) and 32 predation attempts (mean \pm SE: $0.33 \pm 0.06$ attempts lionfish $^{-1} 10 \mathrm{~min}^{-1}$ ) by 96 lionfish, ranging in TL from 13 to $39 \mathrm{~cm}$. Nearly three-quarters $(23$, or $72 \%)$ of these predation attempts were successful, which translates into a predation rate of $1.44 \pm 0.15 \mathrm{SE}$ kills lionfish ${ }^{-1} \mathrm{~h}^{-1}$.

Table 1. Identity of hunting targets and prey of lionfish, derived from field observations and expressed in proportions of hunting bouts and predation events. The total for hunting targets exceeds $100 \%$ because mixed-species groups of fish were often targeted. -: species not caught

\begin{tabular}{|c|c|c|c|}
\hline Hunting target/prey species & $\begin{array}{l}\text { Life stage(s) } \\
\text { targeted }\end{array}$ & $\begin{array}{l}\text { Hunting } \\
\text { targets (\%) }\end{array}$ & $\begin{array}{c}\text { Prey caught } \\
(\%)\end{array}$ \\
\hline \multicolumn{4}{|l|}{ Family Gobiidae } \\
\hline Coryphopterus hyalinus/personatu & Adult & 28.3 & 48 \\
\hline Coryphopterus lipernes & Adult & 0.4 & - \\
\hline Coryphopterus glaucofraenum & Adult & 0.4 & - \\
\hline Elacatinus spp. & Adult & 0.4 & - \\
\hline \multicolumn{4}{|l|}{ Family Labridae } \\
\hline Clepticus parrae & Juvenile/adult & 9.4 & - \\
\hline Halichoeres garnoti & Juvenile & 5.2 & - \\
\hline Thalassoma bifasciatum & Juvenile/adult & 14.2 & 13 \\
\hline \multicolumn{4}{|l|}{ Family Scaridae } \\
\hline Scarus iserti & Juvenile & 9.4 & 8.7 \\
\hline Scarus taeniopterus & Juvenile & 3.9 & - \\
\hline Sparisoma aurofrenatum & Juvenile & 5.2 & - \\
\hline Unidentified parrotfish & Juvenile & 1.3 & - \\
\hline \multicolumn{4}{|l|}{ Family Pomacentridae } \\
\hline Chromis cyanea & Juvenile & 2.1 & - \\
\hline Chromis insolata & Juvenile & 1.7 & - \\
\hline Chromis multilineata & Juvenile & 0.9 & - \\
\hline Stegastes partitus & Juvenile/adult & 3.4 & - \\
\hline \multicolumn{4}{|l|}{ Family Serranidae } \\
\hline Hypoplectrus puella & Juvenile & 0.4 & - \\
\hline \multicolumn{4}{|l|}{ Family Grammatidae } \\
\hline Gramma loreto & Juvenile/adult & 1.3 & 4.3 \\
\hline \multicolumn{4}{|l|}{ Family Synodontidae } \\
\hline Unidentified diver & Juvenile & 0.9 & - \\
\hline \multicolumn{4}{|l|}{ Family Tetraodontidae } \\
\hline Canthigaster rostrata & Adult & 0.4 & - \\
\hline \multicolumn{4}{|l|}{ Family Haemulidae } \\
\hline Haemulon flavolineatum & Juvenile & 0.4 & - \\
\hline Unidentified & - & 35.2 & 26 \\
\hline $\mathrm{N}$ & & $\begin{array}{l}233 \text { hunting } \\
\text { bouts }\end{array}$ & $\begin{array}{l}32 \text { predation } \\
\text { events }\end{array}$ \\
\hline
\end{tabular}


Of the lionfish observed, 24 were inactive for their entire observation period, although some lionfish did attack prey from a stationary position on the substratum. The attack rate of active fish was significantly higher than that of inactive fish (mean $\pm \mathrm{SE}_{\text {; }}$ active: $0.43 \pm 0.08$ attempts $10 \mathrm{~min}^{-1}$, inactive: $0.04 \pm$ 0.04 attempts $10 \mathrm{~min}^{-1}$; Mann-Whitney test, $U=608.5$, $\left.\mathrm{n}_{\text {active }}=72, \mathrm{n}_{\text {inactive }}=24, \mathrm{p}=0.005\right)$. Omitting inactive fish raised the predation rate to $1.92 \pm 0.23$ SE kills lionfish ${ }^{-1} \mathrm{~h}^{-1}$.

The targets of lionfish hunting bouts and predation could be identified on 65 and $74 \%$ of cases, respectively. The majority of prey were small fish (Table 1), which were often slowly herded by lionfish, with pectoral fins widely spread, into a confined space (e.g. against a vertical or concave surface). Strikes occurred rapidly, when lionfish were 10 to $30 \mathrm{~cm}$ from their prey.

On 13 occasions, lionfish approached aggregations of reef fish as these groups formed around cleanerfish such as juvenile bluehead wrasse Thalassoma bifasciatum and cleaning gobies (Elacatinus spp.). In all cases, lionfish changed their swimming direction abruptly and swam quickly towards the fish that were soliciting, with immobile head-stand or tail-stand poses, the attention of cleaners. Aggregations of posing fish usually dispersed when the hunting lionfish was $\geq 50 \mathrm{~cm}$ away. However, on one occasion, lionfish successfully preyed upon the cleanerfish (a juvenile bluehead wrasse).

\section{Correlates of lionfish activity levels and predation rates}

Lionfish observed in the morning spent a similar amount of time being active and hunting as lionfish observed in the afternoon (Table 2). The average distances moved by lionfish and rates of predation attempts were
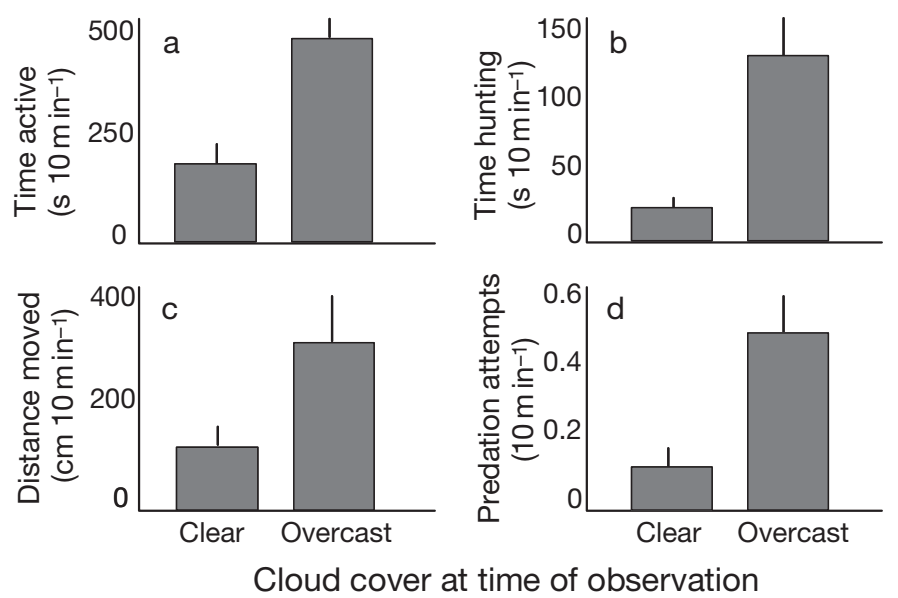

Cloud cover at time of observation

Fig. 1. Activity level and hunting behaviour of introduced lionfish on Bahamian reefs in relation to cloud cover at the time of observation. Overcast skies had $>70 \%$ cloud cover. (a) Time spent active, (b) time spent hunting, (c) distance moved and (d) number of predation attempts. Error bars are $+1 \mathrm{SE}$. Lionfish sample sizes: $\mathrm{n}_{\text {clear }}=41, \mathrm{n}_{\text {overcast }}=55$

also similar during mornings and afternoons (Table 2).

By contrast, cloud cover had a marked effect on lionfish behaviour (Fig. 1). On overcast days, lionfish spent significantly more time active and more time hunting, moved longer distances and attempted predation more frequently than on clear days (Table 2). Approximately $90 \%$ (21 of 23) of successful predation attempts were observed during overcast periods, which is equivalent to a predation rate of $2.29 \pm 0.31 \mathrm{SE}$ kills h$^{-1}$ (vs. $0.29 \pm$ 0.05 kills $\mathrm{h}^{-1}$ during clear periods). There was $83 \%$ agreement between our cloud-cover assessments and the corresponding archived weather information. A total of $57 \%$ of lionfish observations were carried out during overcast times. By comparison, the meteorological archive suggests that only $40 \%$ of days were

Table 2. Comparisons of lionfish activity and foraging behaviour at 2 different times of day and at times of contrasting cloud cover. Data are mean \pm SE. n: number of lionfish observed; $\alpha_{\mathrm{FDR}}$ : critical $\alpha$ level, corrected for false discovery rate (see 'Materials and methods'). na: not applicable

\begin{tabular}{|c|c|c|c|c|c|c|c|c|c|c|}
\hline \multirow[t]{2}{*}{ Lionfish behaviour } & \multirow{2}{*}{$\begin{array}{c}\text { Morning } \\
(\mathrm{n}=58)\end{array}$} & \multirow{2}{*}{\multicolumn{2}{|c|}{$\begin{array}{l}\text { Time of day- } \\
\text { Afternoon Mann- } \\
\text { (n = 38) Whitney } U\end{array}$}} & \multirow[b]{2}{*}{$\mathrm{p}$} & \multirow[b]{2}{*}{$\alpha_{\mathrm{FDR}}$} & \multirow[b]{2}{*}{$\begin{array}{c}\text { Clear } \\
(\mathrm{n}=41)\end{array}$} & \multirow{2}{*}{\multicolumn{2}{|c|}{$\begin{array}{l}\text { Cloud cover } \\
\text { Overcast } \\
\text { (n }=55) \quad \text { Whitney } \\
\end{array}$}} & \multirow[b]{2}{*}{$\mathrm{p}$} & \multirow[b]{2}{*}{$\alpha_{\mathrm{FDR}}$} \\
\hline & & & & & & & & & & \\
\hline $\begin{array}{l}\text { Time spent active } \\
\left(\mathrm{s} 10 \mathrm{~min}^{-1}\right)\end{array}$ & $318.1 \pm 34.8$ & $345.8 \pm 434$ & 1047.5 & 0.67 & na & $173.9 \pm 34.7$ & $444.8 \pm 34.6$ & 476.5 & $<0.001$ & 0.008 \\
\hline $\begin{array}{l}\text { Time spent hunting } \\
\left(\mathrm{s} 10 \mathrm{~min}^{-1}\right)\end{array}$ & $93.7 \pm 14.8$ & $112.6 \pm 14.6$ & 993.5 & 0.40 & na & $25.3 \pm 9.0$ & $123.5 \pm 15.2$ & 491.0 & $<0.001$ & 0.008 \\
\hline $\begin{array}{l}\text { Distance travelled } \\
(\mathrm{m})\end{array}$ & $220.6 \pm 33.4$ & $138.7 \pm 35.1$ & 929.0 & 0.19 & na & $113.1 \pm 32.0$ & $244.0 \pm 34.3$ & 616.5 & $<0.001$ & 0.008 \\
\hline $\begin{array}{l}\text { Rate of predation } \\
\text { attempts (attempts } 1\end{array}$ & $\begin{array}{l}0.3 \pm 0.1 \\
\left.\text { ain }^{-1}\right)\end{array}$ & $0.4 \pm 0.1$ & 1005.5 & 0.35 & na & $0.1 \pm 0.1$ & $0.5 \pm 0.1$ & 793.0 & 0.001 & 0.017 \\
\hline
\end{tabular}


overcast between May 2008 and April $2009\left(\chi^{2}=11.96\right.$, $\mathrm{df}=1, \mathrm{p}<0.001)$. The study period was therefore significantly cloudier than expected for New Providence.

The time lionfish spent active and the distance they moved during observations did not vary with lionfish length (Spearman rank correlations, both $\mathrm{p}>0.44$ ). Similarly, the time spent hunting and the rate of predation attempts were not correlated with lionfish length (Spearman rank correlations, both $\mathrm{p}>0.14$ ). However, lionfish spent more time active $\left(\mathrm{r}_{\mathrm{S}}=0.34, \mathrm{n}=96, \mathrm{p}=\right.$ $\left.0.001, \alpha_{\mathrm{FDR}}=0.016\right)$ and more time hunting $\left(\mathrm{r}_{\mathrm{S}}=0.24\right.$, $\mathrm{n}=96, \mathrm{p}=0.018, \alpha_{\mathrm{FDR}}=0.019$ ) with increasing depth, although depth did not affect either the distance moved $\left(r_{S}=0.23, n=96, p=0.026, \alpha_{F D R}=0.022\right)$ or the rate of predation attempts $\left(r_{S}=0.05, n=96, p=0.65\right)$.

\section{DISCUSSION}

We present a first estimate of predation rates by Indo-Pacific lionfish in their introduced northwest Atlantic range. Lionfish were well established at our study location in the Bahamas (Green \& Côté 2009), although their population densities may still be increasing. Little is known of lionfish behaviour in their native range, hence the baseline for comparisons with behaviour in the introduced range is limited. Nevertheless, 4 of our findings are novel. First, lionfish were active predators during the day. Second, cloud cover appeared to have a strong effect on lionfish activity levels. Third, lionfish appeared to be attracted to fish aggregations at cleaning stations, perhaps using these aggregations as hunting grounds. Finally, lionfish prey consumption rates were very high, which has implications for their impact on native Caribbean reef fish.

In their native range, lionfish are thought to be crepuscular or nocturnal predators (Myers 1991). Fishelson (1997), for example, observed adult lionfish in the Red Sea remaining 'stationary at one site throughout the day, or glid[ing] gently in the reef shadows, often without foraging'. However, in the present study, we obtained measurable predation rates during daylight hours. Because of logistical constraints, we could not observe lionfish between dusk and dawn so it remains possible that lionfish in the Bahamas are even more active at those times than during the day, in which case our estimates of predation should be regarded as conservative. Nevertheless, during 1 crepuscular dive at 1 of the study sites (Bond Wrecks; 17:57 to 18:59 h), the 4 lionfish sighted were all inactive and lying on the substratum. During the day, cloud cover had a pronounced effect on lionfish hunting activity and predation rates, and it is possible that light levels on overcast days approached those of dawn and dusk. An effect of light level is also suggested by the increased activity of lionfish at greater depths. Lionfish in New Providence are therefore perhaps more diurnal than they are thought to be in their native range, although observations of introduced lionfish during crepuscular hours, accurate measurements of illumination, and more observations from the native range are needed to confirm this conclusion.

Lionfish hunted a wide diversity of species. At least 19 fish species, in at least 9 families, were stalked by lionfish, with at least 4 of these species preyed upon. This represents approximately half of the family diversity (21 families) recorded in the stomach contents of lionfish from the Bahamian archipelago (Morris \& Akins 2009). However, the proportion of hunting bouts targeting each species in the present study was positively related to the reported proportion of lionfish diet (in numerical terms) contributed by each species in Morris \& Akins (2009) ( $\mathrm{r}=0.63, \mathrm{n}=19, \mathrm{p}=0.004)$, suggesting that our hunting observations are relatively unbiased. The more limited prey diversity found in the present study may simply reflect more limited sampling, both geographically and temporally.

Lionfish on Bahamian reefs used a variety of hunting tactics. They exhibited the typical hunting behaviour of herding prey using their ornate, oversized pectoral fins, which has been described previously (Allen \& Eschmeyer 1973, Fishelson 1997). They also occasionally acted as a sit-and-wait predator, striking rapidly at passing prey from a stationary position. However, we observed what may be a novel hunting tactic, namely the use of cleaning stations as a potential cue to locate prey. On Caribbean reefs, small groups of fish frequently form around cleaning gobies (Elacatinus spp.) and the juvenile wrasses Thalassoma bifasciatum and Bodianus rufus (Côté 2000). Client fish often adopt immobile, head-down or head-up poses to signal their willingness to be inspected (Côté et al. 1998). These aggregations of posing fish are clearly conspicuous to lionfish, as suggested by the abrupt changes in swimming direction exhibited by lionfish towards cleaning aggregations forming nearby. The arrival of lionfish usually led to the premature departure of clients, and although lionfish did not successfully prey on clients during our observations, one did consume a cleanerfish. Further research should investigate more thoroughly the frequency with which this hunting method is used by lionfish and the repercussions of lionfish disruptions of cleaning activity for both cleaners and clients.

Simple back-of-the-envelope calculations based on our observations yield startling figures of prey consumption by lionfish. The average size of prey eaten in the present study was $\sim 4 \mathrm{~cm}$ (authors' pers. obs.), and the average weight $\sim 1 \mathrm{~g}$ (given the average coefficients of length-weight relationships for the 4 reef fish 
species preyed upon in the present study; weight $=$ $0.015 \times$ length $^{2.998} ;$ Froese \& Pauly 2009). To incorporate the effect of cloud cover and account for the fact that the study period was significantly more cloudy than is usual in New Providence, we can consider separately the per capita predation rates under clear skies (0.29 kills $\left.\mathrm{h}^{-1}\right)$ and overcast skies (2.29 kills $\left.\mathrm{h}^{-1}\right)$. Extrapolating these figures to a $12 \mathrm{~h}$ day, and considering the usual ratio of clear to overcast days at our study site, results in 13.1 kills $\mathrm{d}^{-1}$, or $\sim 13 \mathrm{~g} \mathrm{~d}^{-1}$, for lionfish that were on average $( \pm \mathrm{SE}) 25 \pm 6 \mathrm{~cm}$ TL (or $\sim 340 \mathrm{~g}$, based on the growth curve for Pterois volitans reported by Fishelson 1997). This figure is consistent with the range of prey consumption rates (11.1 to $14.3 \mathrm{~g}$ wet food $\mathrm{d}^{-1}$ ) expected based on oxygen demand of tropical fish of this size with a relatively active lifestyle (Fishelson 2003; see Appendix 1 for calculations). For comparison, the only known prey consumption rate for $P$. volitans, which is derived from fish from the native range but extrapolated from an ad libitum foraging experiment, suggests that adult lionfish (300 to $400 \mathrm{~g}$ ) consume approximately $8.5 \mathrm{~g}$ prey $\mathrm{d}^{-1}$ (Fishelson 1997). Our calculations imply that using published consumption rates from the native range to predict the impacts of lionfish on native Caribbean fish could lead to severe underestimation of these impacts.

The high rate of prey consumption by lionfish documented in the present study, combined with a wide diet breadth (Morris \& Akins 2009) and increasing lionfish densities across invaded reefs (Whitfield et al. 2007, Green \& Côté 2009), suggest that the introduction of lionfish has the potential to exacerbate severely the decade-long declining trend recently noted in Caribbean reef fish densities (Paddack et al. 2009). Since lionfish have few natural predators (Bernadsky \& Goulet 1991, Maljković et al. 2008), the control of lionfish populations will depend on intense and targeted removal efforts (Morris et al. 2009). Without these, many Caribbean reef fish populations face a grim future.

Acknowledgements. We thank S. Cove and M. Cove and the staff at Stuart Cove's Dive Bahamas for invaluable contributions to field logistics, and S. Green for comments that greatly improved the manuscript. The study was funded by an operating grant from the Natural Sciences and Engineering Research Council of Canada to I.M.C.

\section{LITERATURE CITED}

Albins MA, Hixon MA (2008) Invasive Indo-Pacific lionfish Pterois volitans reduce recruitment of Atlantic coral-reef fishes. Mar Ecol Prog Ser 367:233-238

Allen GR, Eschmeyer WN (1973) Turkeyfishes at Eniwetok. Pac Discovery 26:3-11

Benjamini Y, Hochberg Y (1995) Controlling the false discov- ery rate: a practical and powerful approach to multiple testing. J R Stat Soc B 57:289-300

Bernadsky G, Goulet D (1991) A natural predator of the lionfish Pterois miles. Copeia 1991:230-231

Carlton JT (1989) Man's role in changing the face of the ocean: biological invasions and implications for conservation of near-shore environments. Conserv Biol 3:265-273

Côté IM (2000) Evolution and ecology of cleaning symbioses in the sea. Oceanogr Mar Biol Annu Rev 38:311-355

Côté IM, Arnal C, Reynolds JD (1998) Variation in posing behaviour among fish species visiting cleaning stations. J Fish Biol 53(Suppl A):256-266

Courtenay WR (1995) Marine fish introductions in southeastern Florida. Am Fish Soc Introd Fish Sect Newsl 1995(14): $2-3$

> Fishelson L (1997) Experiments and observations on food consumption, growth and starvation in Dendrochirus brachypterus and Pterois volitans (Pteroinae, Scorpaenidae). Environ Biol Fishes 50:391-403

> Fishelson L (2003) Coral and fish biocoenosis: ecological cells gradually maturing in complexity, species composition and energy turnover. Environ Biol Fishes 68:391-405

> Freshwater DW, Hines A, Parham S, Wilbur A and others (2009) Mitochondrial control region sequence analyses indicate dispersal from the US East Coast as the source of the invasive Indo-Pacific lionfish Pterois volitans in the Bahamas. Mar Biol 156:1213-1221

Green SJ, Côté IM (2009) Record densities of Indo-Pacific lionfish on Bahamian coral reefs. Coral Reefs 28:107

> Hamner RM, Freshwater DW, Whitfield PE (2007) Mitochondrial cytochrome $b$ analysis reveals two invasive lionfish species with strong founder effects in the western Atlantic. J Fish Biol 71:214-222

Maljković A, van Leeuwen TE, Cove SN (2008) Predation on the invasive red lionfish, Pterois volitans (Pisces: Scorpaenidae), by native groupers in the Bahamas. Coral Reefs 27:501

> Morris JAJ, Akins JL (2009) Feeding ecology of invasive lionfish (Pterois volitans) in the Bahamian archipelago. Environ Biol Fishes 86:389-398

Morris JAJ, Akins JL, Barse A, Cerino D and others (2009) Biology and ecology of the invasive lionfishes, Pterois miles and Pterois volitans. Proc Gulf Carib Fish Inst 61:409-414

Myers RF (1991) Micronesian reef fishes, 2nd edn. Coral Graphic Barrigada, Guam

Paddack MJ, Reynolds JD, Aguilar C, Appeldoorn RS and others (2009) Recent region-wide declines in Caribbean reef fish abundance. Curr Biol 19:590-595

Ruiz GM, Carlton JT, Grosholz ED, Hines AH (1997) Global invasions of marine and estuarine habitats by nonindigenous species: mechanisms, extent, and consequences. Am Zool 37:621-632

Ruiz GM, Fofonoff P, Hines AH, Grosholz ED (1999) Nonindigenous species as stressors in estuarine and marine communities: assessing invasion impacts and interactions. Limnol Oceanogr 44:950-972

Ruiz GM, Fofonoff PW, Carlton JT, Wonham MJ, Hines AH (2000) Invasion of coastal marine communities in North America: apparent patterns, processes, and biases. Annu Rev Ecol Syst 31:481-531

Ruiz-Carus R, Matheson RE, Roberts DE, Whitfield PE (2006) The western Pacific red lionfish, Pterois volitans (Scorpaenidae), in Florida: evidence for reproduction and parasitism in the first exotic marine fish established in state waters. Biol Conserv 128:384-390

Schmidt-Nielsen K (1984) Scaling: Why is animal size so 
important? Cambridge University Press, Cambridge

Semmens BX, Buhle ER, Salomon AK, Pattengill-Semmens CV (2004) A hotspot of non-native marine fishes: evidence for the aquarium trade as an invasion pathway. Mar Ecol Prog Ser 266:239-244

Vitousek PM, Dantonio CM, Loope LL, Rejmanek M, Westbrooks R (1997) Introduced species: a significant component of human-caused global change. NZ J Ecol 21:1-16

Wabnitz C, Taylor M, Green E, Razak T (2003) From ocean to aquarium. United Nations Environment Programme,
World Conservation Monitoring Centre (UNEP-WCMC), Cambridge

Whitfield PE, Gardner T, Vives SP, Gilligan MR, Courtenay WR, Ray GC, Hare JA (2002) Biological invasion of the Indo-Pacific lionfish Pterois volitans along the Atlantic coast of North America. Mar Ecol Prog Ser 235:289-297

Whitfield PE, Hare JA, David AW, Harter SL, Munoz RC, Addison CM (2007) Abundance estimates of the IndoPacific lionfish Pterois volitans/miles complex in the Western North Atlantic. Biol Invasions 9:53-64

Appendix 1. Calculation of lionfish energetic requirements based on oxygen demand

Following Fishelson (2003), we calculated the predicted energetic requirements based on oxygen demand of an average-sized lionfish (25 cm TL, $340 \mathrm{~g}$ ) on Bahamian reefs.

Oxygen consumption in fishes increases with body mass with an allometric exponent of 0.8 , on average (SchmidtNielsen 1984), thus the 'metabolic' weight of a $340 \mathrm{~g}$ lionfish is $422 \mathrm{~g}$, or $0.422 \mathrm{~kg}$. Fishelson (2003) reported that at water temperatures of 23 to $24^{\circ} \mathrm{C}$, the standard metabolic rate (SMR) of actively feeding reef fish may be upwards of $200 \mathrm{mg} \mathrm{O}_{2} \mathrm{~kg}^{-0.8} \mathrm{~h}^{-1}$. Given an SMR of $200 \mathrm{mg} \mathrm{O}_{2} \mathrm{~kg}^{-0.8}$ $\mathrm{h}^{-1}$, an average-sized lionfish uses $84.4 \mathrm{mg} \mathrm{O}_{2} \mathrm{~h}^{-1}$. This oxygen consumption is equivalent to $323.3 \mathrm{~W} \mathrm{~g}^{-1} \mathrm{~h}^{-1}$ of energy (given that $1 \mathrm{mg} \mathrm{O}^{2}=3.83 \mathrm{~mW}$ energy), or $0.323 \mathrm{~W}$ $\mathrm{kg}^{-1} \mathrm{~h}^{-1}$. Converting to $\mathrm{kJ} \mathrm{h}^{-1}$ (given that $1 \mathrm{~W}=1 \mathrm{~J} \mathrm{~s}^{-1}$ ) gives $1.16 \mathrm{~kJ} \mathrm{~h}^{-1}$. This can in turn be converted into weight of dry food $\mathrm{d}^{-1}$, assuming that $1 \mathrm{~g}$ of dry food provides $\sim 14 \mathrm{~kJ}$. Thus, an average lionfish would need to consume $\sim 1.995 \mathrm{~g}$ dry food $\mathrm{d}^{-1}$. Assuming that the prey organisms are composed of 14 to $18 \%$ dry material, an average lionfish would need to consume between 11.1 and $14.3 \mathrm{~g}$ wet food $d^{-1}$.
Editorial responsibility: Charles Birkeland, Honolulu, Hawaii, USA
Submitted: May 18, 2009; Accepted: December 11, 2009 Proofs received from author(s): March 24, 2010 